\title{
Vasopressors in shock: are we meeting our target and do we really understand what we are aiming at?
}

\author{
Martin Dünser ${ }^{1^{*}}$, Peter Buhl Hjortrup ${ }^{2}$ and Ville Pettilä3,4
}

(C) 2016 Springer-Verlag Berlin Heidelberg and ESICM

The rationale for the use of vasopressors in shock is twofold. First, in a rescue attempt, when arterial blood pressure drops below a critical threshold under which the heart and brain are hypoperfused, vasopressors are administered to restore arterial blood pressure back to levels that maintain coronary and cerebral perfusion, even if this potentiates peripheral vasoconstriction. Second, vasopressors are infused in the intention to reverse excessive vasodilatation in shock. Clinicians assume that systemic blood flow is then redistributed from the muscular, mesenteric, and cutaneous vascular beds to visceral and vital organs. Both in clinical practice $[1,2]$ and clinical trials $[3,4]$, mean arterial blood pressure (MAP) has been the primary parameter to guide resuscitation and titrate vasopressors in shock. However, it is increasingly acknowledged that using MAP as the main resuscitation endpoint in shock implies relevant limitations [5]. As MAP is, in simplified form, the mathematical product of cardiac output and vascular resistance, elevating MAP by increasing vascular resistance carries the detrimental risk of further compromising tissue perfusion in low cardiac output/high vascular resistance states. In addition, no clear relationship between MAP and microcirculatory blood flow has so far been established in patients with shock [6,7]. Similarly, vasopressor-induced changes in MAP have had variable effects on capillary perfusion and single organ function in clinical studies [7]. Finally, it is unlikely that one specific resuscitation endpoint, instead of a physiology-based approach applying individualized

\footnotetext{
*Correspondence: M.Duenser@salk.at

${ }^{1}$ Intensive Care Units, Department of Anesthesiology, Perioperative and General Intensive Care Medicine, University Hospital Salzburg and Paracelsus Private Medical University, Salzburg, Austria Full author information is available at the end of the article
}

endpoints and hemodynamic interventions, will be adequate for all patients in shock.

A recent systematic review identified only two randomized controlled trials comparing different MAP targets for titration of vasopressor drugs in septic shock [8]. In a new article in this journal, the Canadian Critical Care Trials Group presents the results of the OVATION (Optimal Vasopressor TItratiON) open-label randomized controlled trial (RCT) [9]. It was planned as a multicenter feasibility trial to inform the design of a larger study. Over a 16-month period, 120 out of 1017 screened and 238 eligible patients with vasodilatory shock were enrolled. Patients were randomized to vasopressor titration according to a target MAP range of $60-65 \mathrm{mmHg}$ or one of $75-80 \mathrm{mmHg}$. A between group difference in MAP of at least $5 \mathrm{mmHg}$ was used for sample size calculations, and with an observed difference of $9 \mathrm{mmHg}$ (95\% CI 7-11 mmHg) the authors have to be congratulated that they could confirm the feasibility of their study.

However, four study findings deserve consideration. First, during approximately $70 \%$ of the time observed MAP levels were out of the prescribed target MAP range with a mean observed MAP of $70 \pm 5 \mathrm{mmHg}$ in the lower and $79 \pm 5 \mathrm{mmHg}$ in the higher target MAP group. Notably, the majority of MAP 'outliers' were above the target range, in agreement with SEPSISPAM trial findings (mean MAP levels $73-78 \mathrm{mmHg}$ in the $65-70 \mathrm{mmHg}$ target MAP group and $82-87 \mathrm{mmHg}$ in the $80-85 \mathrm{mmHg}$ target MAP group) [10]. Clinical data (and experience) suggest that critical care staff rather considers target MAP range as the lower limit to increase vasopressor dose instead of using it as an upper limit to decrease it $[3,4,10]$. On the basis of previous study results, many intensive care nurses and physicians seem to consider a MAP between 70 and $85 \mathrm{mmHg}$ as the 'comfort zone.' However, vasopressors may have serious

\section{Springer}


Table 1 Issues to be addressed in future MAP trials in critically ill patients

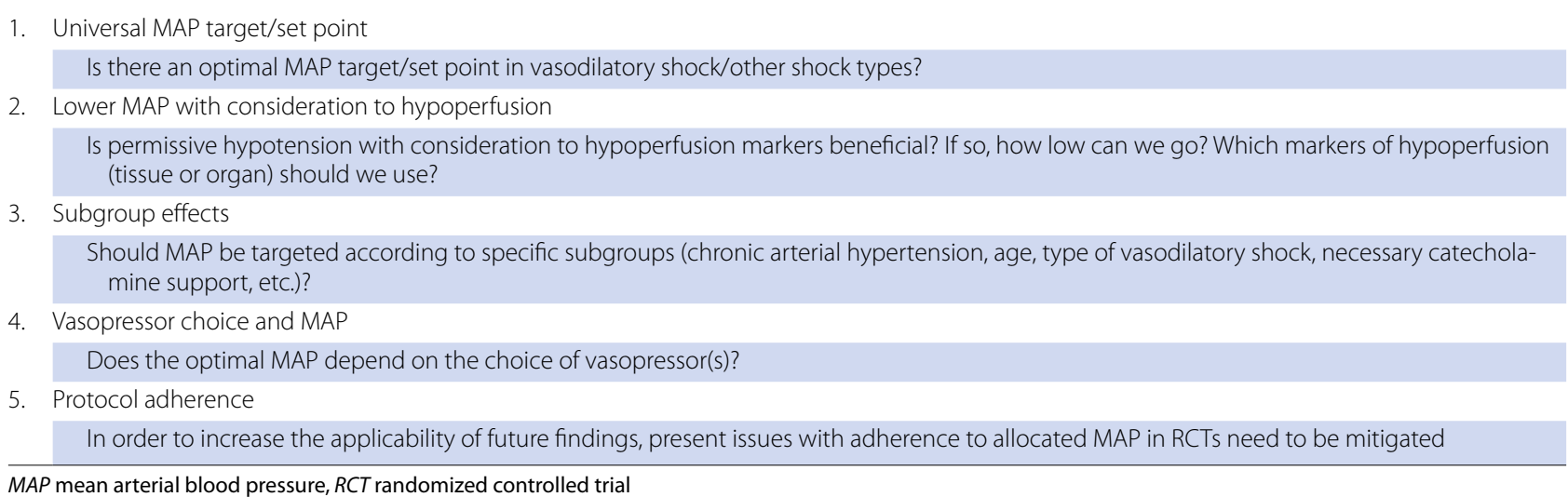

adverse effects in critically ill patients with shock [10-12], and, therefore, titration of these agents to the lowest necessary dose may be beneficial. In contrast to the clinical trials mentioned above $[9,10]$, retrospective observational studies suggest that MAP levels between 60 and $65 \mathrm{mmHg}$ can best predict survival from septic shock $[13,14]$. Elevating MAP above $70 \mathrm{mmHg}$ by intensifying vasopressor therapy was even associated with an increased risk of adverse events [11]. To allow for more definite conclusions, better compliance with the protocol and more data regarding concomitant interventions and actual hemodynamic values are needed in future trials (Table 1).

Another striking finding of this trial was that patients randomized to the $75-80 \mathrm{mmHg}$ MAP range received $40 \%$ higher vasopressor doses and were two additional days on vasopressor support than patients allocated to the lower MAP range, in line with the findings of the SEPSISPAM trial. An increased treatment intensity to achieve higher MAP levels did not only include vasopressor drugs but also blood transfusions (49\% in the lower and versus $71 \%$ in the higher MAP group). Contrary to this finding, the SEPSISPAM trial found no indication of increased transfusions in the higher MAP group.

Third, the definition of vasodilatory shock in this study was not standardized and left to the judgement of the attending physicians. This may be problematic as vasodilatory shock summarizes a multitude of diseases. Even the largest subgroup of patients with vasodilatory septic shock may actually represent two distinct populations. Despite comparable macrohemodynamics, patients may relevantly differ in their lactate levels and thereby microcirculatory derangements, organ dysfunction, and mortality [15]. Various vasopressors and vasopressor combinations were administered. However, vasopressors differ in their pharmacology and safety profiles which makes interpretation and extrapolation of the study results difficult.
Finally, the subgroup analysis suggesting improved hospital survival in patients over 75 years and randomized to the 60-65 $\mathrm{mmHg}$ MAP range deserves notification. The age limit of 75 years appears arbitrarily chosen and not supported by strong biological plausibility. Additionally, the number of patients in this subgroup was inadequate $(n=25)$. The objective to identify a population at specific risk for adverse vasopressor effects is though clinically relevant. Observational studies have suggested that age per se is not an independent risk factor for the occurrence of adverse events during vasopressor therapy [11, 12], which emphasizes the need for large-scale RCTs with predefined subgroups and stratification by subgroup before any conclusions can be made. Instead, the intensity of vasopressor therapy and the disease severity may be the most relevant independent risk factors to predict complications. Because observational studies have their inherent bias, both treatment targets (including different MAP levels and other perfusion-based targets) and different treatments need to be tested in future randomized trials.

\footnotetext{
Author details

${ }^{1}$ Intensive Care Units, Department of Anesthesiology, Perioperative and General Intensive Care Medicine, University Hospital Salzburg and Paracelsus Private Medical University, Salzburg, Austria. ${ }^{2}$ Department of Intensive Care, Copenhagen University Hospital, Rigshospitalet, Copenhagen, Denmark. ${ }^{3}$ Department of Intensive Care Medicine, Bern University Hospital (Inselspital), University of Bern, Bern, Switzerland. ${ }^{4}$ Division of Intensive Care Medicine, Department of Perioperative, Intensive Care and Pain Medicine, University of Helsinki and Helsinki University Hospital, Helsinki, Finland.
}

\section{Compliance with ethical standards}

Conflicts of interest

None of the authors has a conflict of interest to declare.

Received: 7 February 2016 Accepted: 9 February 2016

Published online: 1 March 2016 


\section{References}

1. Torgersen C, Dünser MW, Schmittinger CA, Pettilä V, Ruokonen E, Wenzel V, Jakob SM, Takala J (2011) Current approach to the haemodynamic management of septic shock patients in European intensive care units: a cross-sectional, self-reported questionnaire-based survey. Eur J Anaesthesiol 28:284-290

2. Mclntyre LA, Hébert PC, Fergusson D, Cook DJ, Aziz A, Canadian Critical Care Trials Group (2007) A survey of Canadian intensivists' resuscitation practices in early septic shock. Crit Care 11:R74

3. Russell JA, Walley KR, Singer J, Gordon AC, Hébert PC, Cooper DJ, Holmes CL, Mehta S, Granton JT, Storms MM, Cook DJ, Presneill JJ, Ayers D, Investigators VASST (2008) Vasopressin versus norepinephrine infusion in patients with septic shock. N Engl J Med 358:877-887

4. De Backer D, Biston P, Devriendt J, Madl C, Chochrad D, Aldecoa C, Brasseur A, Defrance P, Gottignies P, Vincent JL, SOAPII Investigators (2010) Comparison of dopamine and norepinephrine in the treatment of shock. N Engl J Med 362:779-789

5. Dünser MW, Takala J, Brunauer A, Bakker J (2013) Re-thinking resuscitation: leaving blood pressure cosmetics behind and moving forward to permissive hypotension and a tissue perfusion-based approach. Crit Care $17: 326$

6. De Backer D, Creteur J, Preiser JC, Dubois MJ, Vincent JL (2002) Microvascular blood flow is altered in patients with sepsis. Am J Respir Crit Care Med 166:98-104

7. Kato R, Pinsky MR (2015) Personalizing blood pressure management in septic shock. Ann Intensive Care 5:41

8. D'Aragon F, Belley-Cote EP, Meade MO, Lauzier F, Adhikari NK, Briel M, Lalu M, Kanji S, Asfar P, Turgeon AF, Fox-Robichaud A, Marshall JC, Lamontagne F, Canadian Critical Care Trials Group (2015) Blood pressure targets for vasopressor therapy: a systematic review. Shock 43:530-539

9. Lamontagne F, Meade OM, Hébert PC, Asfar P, Lauzier F, Seely AJE, Day AG, Mehta S, Muscedere J, Bagshow SM, Ferguson ND, Cook DJ, Kanji S, Turgeon AF, Herridge MS, Subramanian S, Lacroix J, Adhikari NKJ, Scales
DC, Fox-Robichaud A, Skrobik Y, Whitlock RP, Green R, Koo KKY, Tanguay T, Magder S, Heyland D, Canadian Critical Care Trials Group (2016) Higher versus lower blood pressure targets for vasopressor therapy in shock: a multicentre pilot randomized controlled trial. Intensive Care Med. doi:10.1007/s00134-016-4237-3

10. Asfar P, Meziani F, Hamel JF, Grelon F, Megarbane B, Anguel N, Mira JP, Dequin PF, Gergaud S, Weiss N, Legay F, Le Tulzo Y, Conrad M, Robert R, Gonzalez F, Guitton C, Tamion F, Tonnelier JM, Guezennec P, Van Der Linden T, Vieillard-Baron A, Mariotte E, Pradel G, Lesieur O, Ricard JD, Hervé F, du Cheyron D, Guerin C, Mercat A, Teboul JL, Radermacher P, SEPSISPAM Investigators (2014) High versus low blood-pressure target in patients with septic shock. N Engl J Med 370:1583-1593

11. Dünser MW, Ruokonen E, Pettilä V, Ulmer H, Torgersen C, Schmittinger CA, Jakob S, Takala J (2009) Association of arterial blood pressure and vasopressor load with septic shock mortality: a post hoc analysis of a multicenter trial. Crit Care 35:R181

12. Schmittinger CA, Torgersen C, Luckner G, Schröder DC, Lorenz I, Dünser MW (2012) Adverse cardiac events during catecholamine vasopressor therapy: a prospective observational study. Intensive Care Med 38:950-958

13. Varpula M, Tallgren M, Saukkonen K, Voipio-Pulkki LM, Pettilä V (2005) Hemodynamic variables related to outcome in septic shock. Intensive Care Med 31:1066-1071

14. Dünser MW, Takala J, Ulmer H, Mayr VD, Luckner G, Jochberger S, Daudel F, Lepper P, Hasibeder WR, Jakob SM (2009) Arterial blood pressure during early sepsis and outcome. Intensive Care Med 35:1225-1233

15. Hernandez G, Bruhn A, Castro R, Pedreros C, Rovegno M, Kattan E, Veas E, Fuentealba A, Regueira T, Ruiz C, Ince C (2012) Persistent sepsis-induced hypotension without hyperlactatemia: a distinct clinical and pathophysiological profile within the spectrum of septic shock. Crit Care Res Pract 2012:536852 